\title{
Apoptosis induced by lycorine in KM3 cells is associated with the G0/G1 cell cycle arrest
}

\author{
YAN LI* , JING LIU*, LI-JUN TANG, YI-WU SHI, WEI REN and WEI-XIN HU \\ Molecular Biology Research Center, School of Biological Science and Technology, Central \\ South University, 110 Xiangya Road, Changsha, Hunan 410078, P.R. China
}

Received September 20, 2006; Accepted November 2, 2006

\begin{abstract}
Lycorine is a natural anti-tumor alkaloid extracted from Amaryllidaceae and has various biological effects on malignant cells. The present study explores the effects of lycorine on the human multiple meyloma cell line, KM3, and the possible mechanisms of these effects. An MTT assay showed that lycorine had significant inhibitory activity on KM3 cells. The growth rates of the KM3 cells exposed to lycorine evidently slowed down. Cell fluorescent apoptotic morphological changes, DNA degradation fragments, and a sub-G1 peak were detected, indicating the occurrence of cell apoptosis after lycorine treatment. Furthermore, the release of mitochondrial cytochrome $\mathrm{c}$, the augmentation of Bax with the attenuation of Bcl-2, and the activation of caspase-9, -8, and -3 were also detected, suggesting that the mitochondrial pathway and the death acceptor pathway were also involved. The results also showed that lycorine was able to block the cell cycle at the G0/G1 phase through the downregulation of both cyclin D1 and CDK4. In summary, lycorine can suppress the proliferation of KM3 cells and reduce cell survival by arresting cell cycle progression as well as inducing cell apoptosis.
\end{abstract}

\section{Introduction}

Multiple myeloma (MM), a hematological disorder, is characterized by the malignant proliferation of monoclonal plasma cells in bone marrow. Currently, MM represents over $10 \%$ of the malignant tumors in hematological systems around the world. It is the second most frequent hematological malignancy, with a 5 -year survival rate of $<20 \%(1,2)$. With

Correspondence to: Dr Wei-Xin Hu, Molecular Biology Research Center, School of Biological Science and Technology, Central South University, 110 Xiangya Road, Changsha, Hunan 410078, P.R. China E-mail: weixinhu@xysm.net weixinhu@yahoo.com.cn

${ }^{*}$ Contributed equally

Key words: lycorine, multiple myeloma, KM3 cell line, apoptosis, cell cycle the aging of the population, the incidence of MM inevitably rises. Therefore, the perniciousness of MM is still a serious issue in the world (3).

Plasma cells undergo a multistep transformation process before myeloma is formed. The presence of somatic hypermutations of immunoglobulin variable-region genes is consistent with an immortalizing event during plasma cell generation in the germinal centers of the lymph nodes $(4,5)$. Genomic instability is already present in monoclonal gammopathy of undetermined significance (MGUS) $(6,7)$. MGUS cannot be distinguished from myeloma at the gene-expression level, although the plasma cells of both MGUS and myeloma can be clearly distinguished from healthy bone marrow plasma cells (8). Evidence demonstrating that myeloma cells have short telomeres and that healthy plasma cells have long telomeres, could be applied to MGUS, in order to help distinguish subsets with different propensities for progression to overt disease (9).

The failure of myeloma cells to undergo apoptosis plays an important role in their accumulation within the bone marrow (10). The Bcl-2 family proteins, consisting of antiapoptotic and pro-apoptotic members, determine the life or death of a cell (11). Bcl-2 is a highly conserved, ubiquitous membrane protein associated most often with the outer membranes of mitochondria and of nuclei and with the endoplasmic reticulum that regulates apoptosis (12). $\mathrm{Bcl}-2$ is a survival factor for many cell types, and the overexpression of Bcl-2 in cancer cells can result in chemoresistance (13). Bcl-2 plays a major role in drug resistance both in myeloma cell lines and in freshly isolated myeloma cells. Furthermore, apoptosis induced by dexamethasone (14-16), paclitaxel (16), and adenovirus-mediated p53 (Ad-p53) is blocked in the cells expressing high levels of Bcl-2 and in Bcl-2-transfected cell lines $(17,18)$.

Investigations into the molecular mechanisms governing the G1 to $\mathrm{S}$ phase progression in mammalian cells demonstrated a central role for D-type cyclins and for cyclin-dependent kinases (CDKs) 4 and $6(19,20)$. The cell-cycle-accelerating function of cyclin D-associated kinases is mediated by the phosphorylation and concomitant inactivation of the retinoblastoma protein $(\mathrm{pRb})$ in the $\mathrm{G} 1$ phase, a process negatively regulated by $\mathrm{p} 16^{\mathrm{INK} 4 \mathrm{~A}}$ and other $\mathrm{CDK}$ inhibitors. The emerging critical role of the cyclin $\mathrm{D} 1, \mathrm{pRb}$, and $\mathrm{p} 16^{\mathrm{INK} 4 \mathrm{~A}}$ pathway in cell cycle regulation is further supported by the frequent alterations of the individual components of this checkpoint 
mechanism in human tumors $(21,22)$. pRb, p16 ${ }^{\mathrm{INK} 4 \mathrm{~A}}$, cyclin D1, and the CDKs 4 and 6 constitute a G1 regulatory pathway commonly targeted by myeloma tumorigenesis (23).

Lycorine, an alkaloid extracted from amaryllis plants, has been shown to exhibit various natural anti-tumor activities. Lycorine can halt protein synthesis in eukaryotic cells by inhibiting peptide bond formation (24), suppress viral protein synthesis in poliovirus-infected Hela cells (25), stop the acetylcholinesterase enzyme action $(26,27)$, and exhibit antimalarial activity (28). Alternatively, lycorine can inhibit the protein synthesis and cell apoptosis of MM46 in the presence of calprotectin (29). Lycorine can suppress leukemia cell growth and reduce cell survival by arresting the cell cycle and inducing the apoptosis of tumor cells (30).

The human MM cell line, KM3, is one of the pre-B lymphoid cell lines having such differentiation capabilities and is an eternal cell line derived from the bone marrow of clinical MM patients (31). In the present study, we used the KM3 cell line as a model to observe the effect of lycorine on MM cells and to explore its possible molecular mechanisms. Our data demonstrate that lycorine can use different pathways to induce apoptosis and cell cycle arrest in KM3 cells.

\section{Materials and methods}

Cell lines and chemicals. The human MM cell line KM3 was supplied by Dr J. Hou (Department of Hematology, Changzheng Hospital, The Second Military Medical University, Shanghai, P.R. China). The human embryonic kidney epithelial cell line, HEK293, and the fibroblast cell line, NIH/3T3, were from the American Type Culture Collection (ATCC, USA). The KM3, NIH3T3, and HEK293 cells were cultured in RPMI1640 medium (Gibco, USA) supplemented with $10 \%$ fetal calf serum. All culture media contained $100 \mathrm{U} / \mathrm{ml}$ penicillin, $100 \mu \mathrm{g} / \mathrm{ml}$ streptomycin, and $4 \mu \mathrm{g} / \mathrm{ml}$ amphotericin $\mathrm{B}$. The cell lines were carefully cultured in a humidified atmosphere containing $5 \% \mathrm{CO}_{2}$ at $37^{\circ} \mathrm{C}$. Lycorine (Latoxan, France) was dissolved at $0.03 \mathrm{M}$ in dimethyl sulfoxide (DMSO; Sigma, USA) as a stock solution and then diluted in serum-free RPMI1640 medium just before use. Melphalan was purchased from Sigma.

Cell survival rate and cytotoxicity assay (MTT). The cell survival rate and cytotoxicity were measured using the 3-(4, 5-dimethyl-2-thiazolyl)-2, 5-diphenyl tetrazolium bromide (MTT) assay, with slight modifications. Briefly, exponentially growing KM3, NIH3T3, and HEK293 cells were seeded at $1 \times 10^{5}$ cells/well in a 96-well tissue culture plate (BioCoat, USA) with a total volume of $200 \mu 1$ per well. Lycorine concentrations ranging from low to high concentrations (5 assay points) were added immediately. The same process was used for melphalan. After the cells were incubated for $48 \mathrm{~h}$, the relative cell viability was measured by scanning with an ELISA reader using a 570-nm filter, and we calculated the $50 \%$ inhibitory concentration $\left(\mathrm{IC}_{50}\right)$ of lycorine on the cells. Values were expressed as the percentages of the drug-treated cells relative to those of the untreated cells $(100 \%)$.

Inhibition of growth curve. Exponentially growing KM3 cells were seeded at $0.5 \times 10^{5}$ cells/well in a 12 -well tissue culture plate (BioCoat) with a total volume of $1000 \mu 1$ per well. A final concentration of $1.25 \mu \mathrm{M}$ lycorine was added immediately to 6 parallel wells. Another 6 wells were used as the controls. After incubation for each $24 \mathrm{~h}$ (5 assay points), the cells were immediately counted using the trypan blue dye exclusion method, and a cell growth curve was drawn.

Detection of apoptotic cells by fluorescence staining. The apoptotic morphology of the cells exposed to the indicated concentrations of lycorine for $24 \mathrm{~h}$ was monitored by Hochest33258 (Sigma) staining and then observed with fluorescent microscopy, as previously described (32). For each experiment, the cells were stained in a culture medium containing $1 \mathrm{mg} / \mathrm{ml}$ of the dye, and at least 500 cells with condensed/fragmented nuclei were scored to determine apoptosis.

Determination of DNA fragmentation. More than $1 \times 10^{7} \mathrm{KM} 3$ cells were harvested which had been incubated for $48 \mathrm{~h}$ either with different lycorine concentrations or without lycorine. Total DNA was extracted according to the procedure used by Sellins and Cohen (33). DNA fragmentation was analyzed on $2 \%$ agarose gels, and then visualized under UV light by ethidium bromide staining.

Analysis of apoptotic cells by flow cytometry. As indicated, at different times or concentrations, the cells were harvested and washed $3 \mathrm{x}$ with phosphate-buffered saline (PBS). Then the cells were fixed with $70 \%$ cold alcohol at $4^{\circ} \mathrm{C}$ for $24 \mathrm{~h}$. Before assessment, the cells were incubated with $100 \mu \mathrm{g} / \mathrm{ml}$ RNase A at $37^{\circ} \mathrm{C}$ for $30 \mathrm{~min}$ and then stained with $50 \mu \mathrm{g} / \mathrm{ml}$ propidium iodide (PI; Sigma) at $4^{\circ} \mathrm{C}$ for $20 \mathrm{~min}$, and kept away from light. The cell cycle was measured with FACScaliber flow cytometry and analyzed by Cell Quest software.

Release of cytochrome c from mitochondria. KM3 cells, treated with lycorine for $24 \mathrm{~h}$, were harvested, washed with cold PBS, and centrifuged. The cell pellets were smeared on a slide and fixed with $4 \%$ formaldehyde for $30 \mathrm{~min}$. Nonspecific antigens were blocked by 1:20 normal serum diluted with PBS for $10 \mathrm{~min}$ at room temperature. Then the cytochrome $\mathrm{c}$ in the cytoplasm was measured using the cytochrome c assay kit (BioVision, USA). The protein distribution was measured using a confocal laser microscope with an excitation light at a wavelength of $554 \mathrm{~nm}$.

Detection of caspase activity. The caspase assay system (BioVision) was applied to determine caspase activities according to the manufacturer's instructions. The cleavage activities of IETD-pNA, LEHD-pNA, and DEVD-pNA were measured by using the FLICE/caspace-8, Mch6/caspase-9, and CPP32/caspase-3 colorimetric assay kit, respectively. Exponentially growing KM3 cells $\left(5 \times 10^{6}\right)$ in $5 \mathrm{ml}$ were treated with lycorine $(5 \mu \mathrm{M})$ or without lycorine as control for 0,6 , 12,18 , and $24 \mathrm{~h}$ at $37^{\circ} \mathrm{C}$. At the indicated time points, the cells were pelleted by centrifugation and resuspended in a $50 \mu 1$ chilled cell lysis buffer. The protein concentration was measured using the BCA protein assay kit (Pierce, USA). Protein $(100 \mu \mathrm{g})$ was diluted with $50 \mu \mathrm{l}$ cell lysis buffer for each assay, and $50 \mu 12 \mathrm{x}$ reaction buffer supplemented with 
A

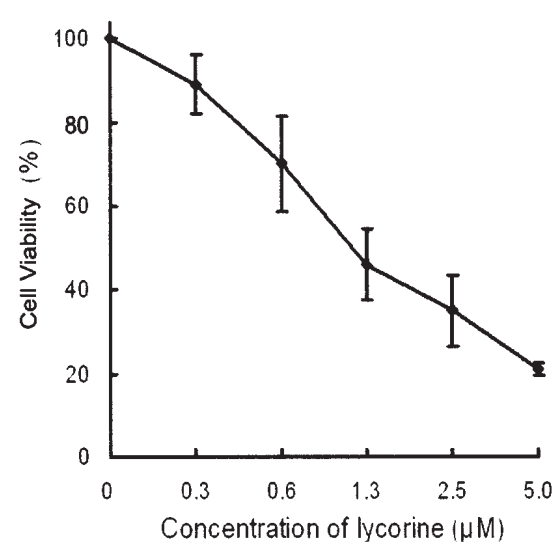

B

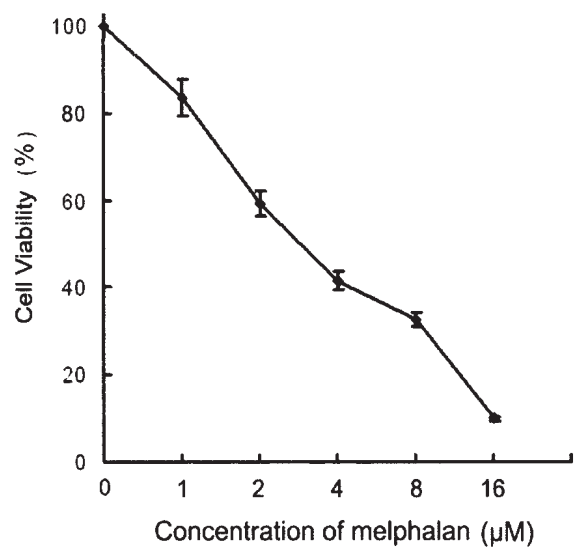

Figure 1. The effects of lycorine or malphalan on the cell survival rates of the human multiple meyloma cell line, KM3. The KM3 cells were cultivated in RPMI-1640 medium with indicated concentrations of lycorine or melphalan for $24 \mathrm{~h}$. The cell survival rate was calculated by MTT assay. (A) The effects of lycorine on the cell survival rates of the KM3 cells. (B) The effects of melphalan on the cell survival rates of the KM3 cells. The values are expressed as the means \pm S.D. of 3 independent experiments.

$10 \mathrm{mM}$ DTT was then added to each tube incubated at $4^{\circ} \mathrm{C}$. The substrates of IETD-pNA, LEHD-pNA, and DEVD-pNA were added into the tubes $(5 \mu 1$ and $50 \mu \mathrm{M})$, respectively, and then incubated at $37^{\circ} \mathrm{C}$ for $1.5 \mathrm{~h}$. The formation of p-nitroanilide in the samples was measured with an ELISA Microplate Reader (EC-800, USA) at $405 \mathrm{~nm}$. The values were expressed as the percentages of caspase- $8,-9,-3$ activities relative to those of the untreated cell extract $(100 \%)$.

Western immunoblot analysis. Exponentially growing KM3 cells $\left(2 \times 10^{6}\right)$ treated with $0,2.5$ and $5 \mu \mathrm{M}$ lycorine for $24 \mathrm{~h}$, were pelleted by centrifugation, washed $3 \mathrm{x}$ with $2 \mathrm{ml}$ PBS, resuspended in $100 \mu 1$ lysis buffer containing $20 \mathrm{mM}$ HEPES, pH 7.4; $100 \mathrm{mM} \mathrm{NaCl} ; 1 \%$ Nonidet P-40; $2 \%$ sodium dodecyl sulfate (SDS); $1 \%$ deoxycholic acid; $10 \%$ glycerol; $1 \mathrm{mM}$ EDTA; $1 \mathrm{mM}$ EGTA; $1 \mathrm{mM}$ sodium orthovanadate; $50 \mathrm{mM}$ sodium fluoride; $1 \mathrm{mM}$ phenylmethylsulfonyl fluoride (PMSF); $10 \mathrm{mg} / \mathrm{ml}$ leupeptin; $1 \mathrm{mg} / \mathrm{ml}$ aprotinin, and sonicated. The protein concentration was measured using a micro BCA kit (Pierce). Protein $(80 \mu \mathrm{g})$ was electrophoresed for $2 \mathrm{~h}$ on $12 \%$-SDS polyacrylamide gels, then transferred to polyvinylidene difluoride membranes (Millipore, USA) using a semi-dry electroblotter for $12 \mathrm{~h}$ at $4^{\circ} \mathrm{C}$. Antibodies (Santa Cruz Biotechnology, USA) raised against Bcl-2, Bax, cyclin D1 (1:200), CDK4 (1:500), or $\alpha$-tubulin (1:4000), were diluted in phosphate-buffered saline Tween-20 (PBST) containing $5 \%$ non-fat milk in all the cases. The membranes were incubated for $2 \mathrm{~h}$ with gentle agitation. The blots were washed $3 \mathrm{x}$ (10 min each) with PBST and incubated with sheep antimouse conjugated to horseradish peroxidase (Santa Cruz Biotechnology; 1:2000 dilution in PBST containing 5\% non-fat milk) for 2 h. After 3 successive washings with PBST, a chemiluminescence reagent (ECL) was used for signal detection. The optical density of the immunoradiograms was quantified by densitometric scanning.

Statistical analysis. The results were expressed as the means \pm $\mathrm{SD}$. The statistical differences between the groups were determined by the one-way analysis of variance (ANOVA) and Tukey's Studentized Range test. Differences among the groups were considered statistically significant at $\mathrm{P}<0.05$.

\section{Results}

Lycorine effectively decreased cell survival rate. MTT assays showed the survival rate of the KM3 cells exposed to lycorine $(0.3-5 \mu \mathrm{M})$ for $48 \mathrm{~h}$. This exposure was reduced in a dose-dependent manner, and thus the viability of the cells was decreased from $89 \pm 6.5$ to $21 \pm 1.4 \%$ (Fig. 1A), with an $\mathrm{IC}_{50}$ value of $1.25 \mu \mathrm{M}$. We also examined the effects of lycorine on 2 other non-tumor cell lines, the mouse fibroblast cell line, NIH3T3, and the human recombinant cell line, HEK293. Among the tested cell lines, KM3 proved to be the most sensitive to the inhibitory effects of lycorine, compared to the little sensitivity detected in the non-tumor cells, NIH3T3 and HEK293, which is indicative of the selective toxicity of lycorine (data not shown).

Melphalan, frequently used in the clinical treatment of MM, was tested as the positive control. After $48 \mathrm{~h}$, the survival rate of the KM3 cells treated with 1 to $16 \mu \mathrm{M}$ melphalan at a half-effective concentration of $3.2 \mu \mathrm{M}$, dropped from $84.2 \pm 6.5 \%$ to $10.2 \pm 3.3 \%$ (Fig. 1B). When comparing the $\mathrm{IC}_{50}$ values of lycorine and melphalan, it is obvious that the tumor cells were more sensitive to lycorine-induced cytotoxicity than to melphalan. $\mathrm{The} \mathrm{IC}_{50}$ value of lycorine was $\sim 1 / 2.5$ that of the melphalan value. Thus, the cellular toxicity of lycorine is $2.5 \mathrm{x}$ greater than that of melphalan. Therefore, lycorine demonstrates a stronger suppressive effect on MM cells.

Cell proliferation inhibited by lycorine. The KM3 cells were treated with $1.25 \mu \mathrm{M}$ lycorine and examined by cell counting every day for 5 days. Cell proliferation was significantly inhibited in a time-dependent manner. The density of the lycorine-treated KM3 cells decreased significantly to about one half the density of the control (Fig. 2). 


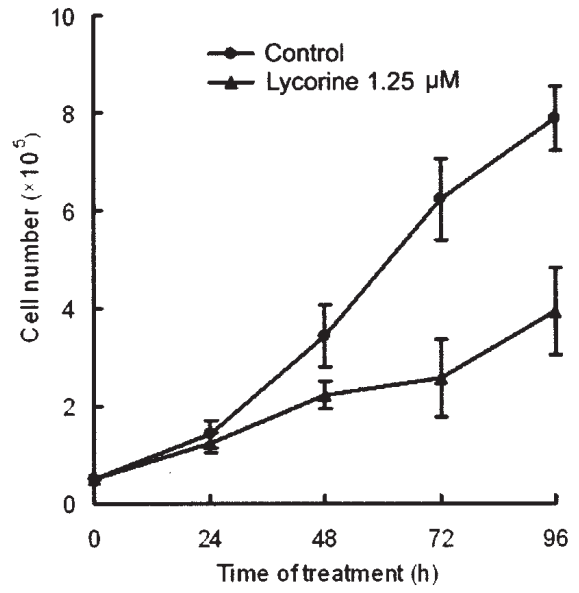

Figure 2. The effects of lycorine on the proliferation of the KM3 cells. The KM3 cells were treated by $1.25 \mu \mathrm{M}$ lycorine for the indicated time. The cell proliferation was estimated by the trypan blue dye exclusion method. The curve shows the growth and proliferation of the KM3 cells inhibited by $1.25 \mu \mathrm{M}$ lycorine in a time-dependent manner. The values are expressed as the means \pm S.D. of 3 independent experiments.
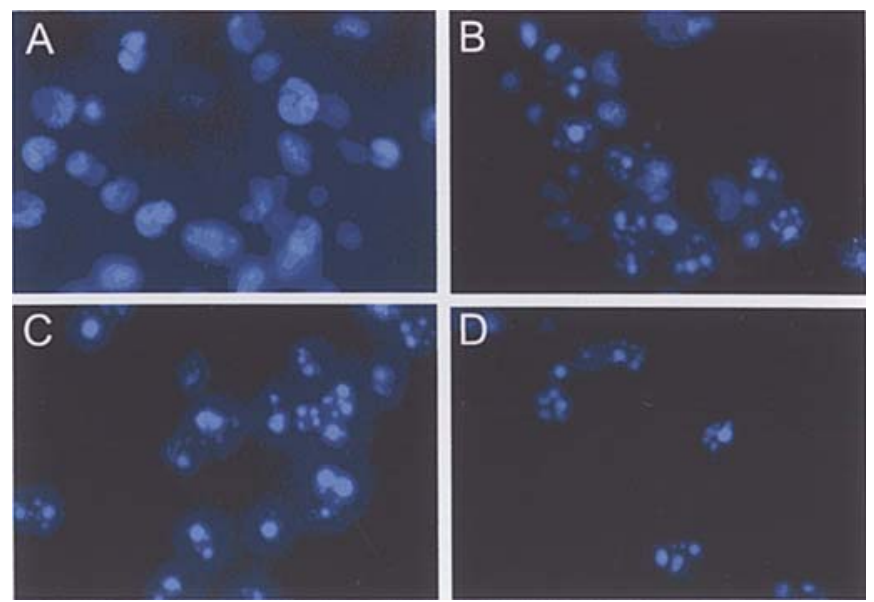

Figure 3. Lycorine-induced apoptosis of the KM3 cells by Hochest33258 staining. The KM3 cells were cultured for $48 \mathrm{~h}$ with the indicated concentration of lycorine. (A) Cultures without drugs as the control (5.7\% apoptosis). (B) Cultured with $2.5 \mu \mathrm{M}$ lycorine, the cells showed a light condensation of chromatin and nuclei margination (32.8\% apoptosis). (C) Cultured with $5 \mu \mathrm{M}$ lycorine, the cells showed fragmented chromatin and apoptotic bodies (50.4\% apoptosis). (D) Typical apoptotic bodies in most of the KM3 cells were seen after treatment with $10 \mu \mathrm{M}$ lycorine (66.1\% apoptosis) (x400).

Enhancement of apoptosis induced by lycorine. We examined the efficacy of the lycorine-induced apoptosis of the KM3 cells by staining the cells with Hochest 33258 and observing them with a fluorescence microscope. All the cells and their nuclei were dyed blue. Normal morphology and nuclei were observed in the control group (Fig. 3A). The $2.5 \mu \mathrm{M}$ group (Fig. 3B) showed light nuclear margination, whereas typical apoptotic cells with fragmented chromatin or apoptotic bodies were seen after the $5 \mu \mathrm{M}$ and $10 \mu \mathrm{M}$ lycorine treatments (Fig. 3C and D). The apoptosis rate in the KM3 cells (including the cells in early apoptosis) was dose-dependent.

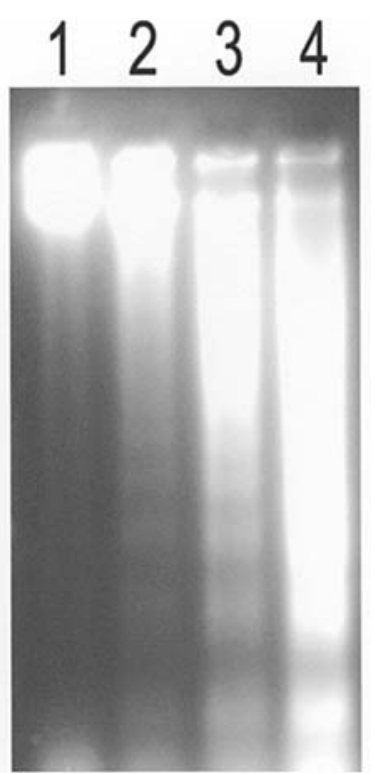

Figure 4. DNA fragmentation of the KM3 cells induced by lycorine. After lycorine treatment for $48 \mathrm{~h}$, the cellular DNA was extracted and ran on $1.5 \%$ agarose gels, and subsequently visualized under UV light by ethidium bromide staining. Lane 1, without treatment as the control; lane 2, $2.5 \mu \mathrm{M}$ lycorine treatment; lane 3,5 $\mu \mathrm{M}$ lycorine treatment; lane 4, $10 \mu \mathrm{M}$ lycorine treatment.

Agarose gel electrophoresis was used to observe DNA fragmentation, a typical step on the ladder during cell apoptosis. DNA fragmentation was observed when lycorine was applied at a concentration of $2.5 \mu \mathrm{M}$. However, when a higher concentration of lycorine ( 5 or $10 \mu \mathrm{M})$ was applied, the DNA ladder was obvious (Fig. 4).

Apoptotic rate change and cell cycle arrest. We found that the apoptotic rates increased from 10.8 to $43.2 \%$ in a dosedependent manner $(0,2.5,5$ and $10 \mu \mathrm{M})$ after $48 \mathrm{~h}$ of processing (Fig. 5A), and from $11.1 \%$ to $45.4 \%$ in a timedependent manner $(0,24,48$ and $72 \mathrm{~h})$ after treatment with $5 \mu \mathrm{M}$ lycorine (Fig. 5B). The flow cytometry assay also showed an increase in the population of cells at the G0/G1 phase, ranging from 28.6 to $41.4 \%$ in a time-response manner, after the KM3 cells were treated with $1.25 \mu \mathrm{M}$ lycorine (Fig. 5C), and from 25.4 to $62.5 \%$ in a dose-response manner after the application of different concentrations of lycorine for $48 \mathrm{~h}$ (Fig. 5D), demonstrating that the cell cycle was being arrested at the G0/G1 phase after the lycorine treatment.

Influences in activation of caspase-8, -9, and -3 . A remarkable activation of caspase- 8 and -3 in the lysates from the KM3 cells treated with $5 \mu \mathrm{M}$ lycorine was recorded at the indicated time points (Fig. 6). We could see that the high points of caspase- 8 and -3 were at the $24-\mathrm{h}$ elapsed treatment time, whereas the activation of caspase- 9 increased slightly. The activation of caspase- 3 increased the most significantly and the most quickly, representing a crucial factor in the caspasecascade downstream pathway (34).

Release of cytochrome c from mitochondria. We examined the subcellular localization of cytochrome $\mathrm{c}$ to determine whether the cytochrome $\mathrm{c}$ was released from the mitochondria to the cytosol in the apoptosis pathway initiated by lycorine. 

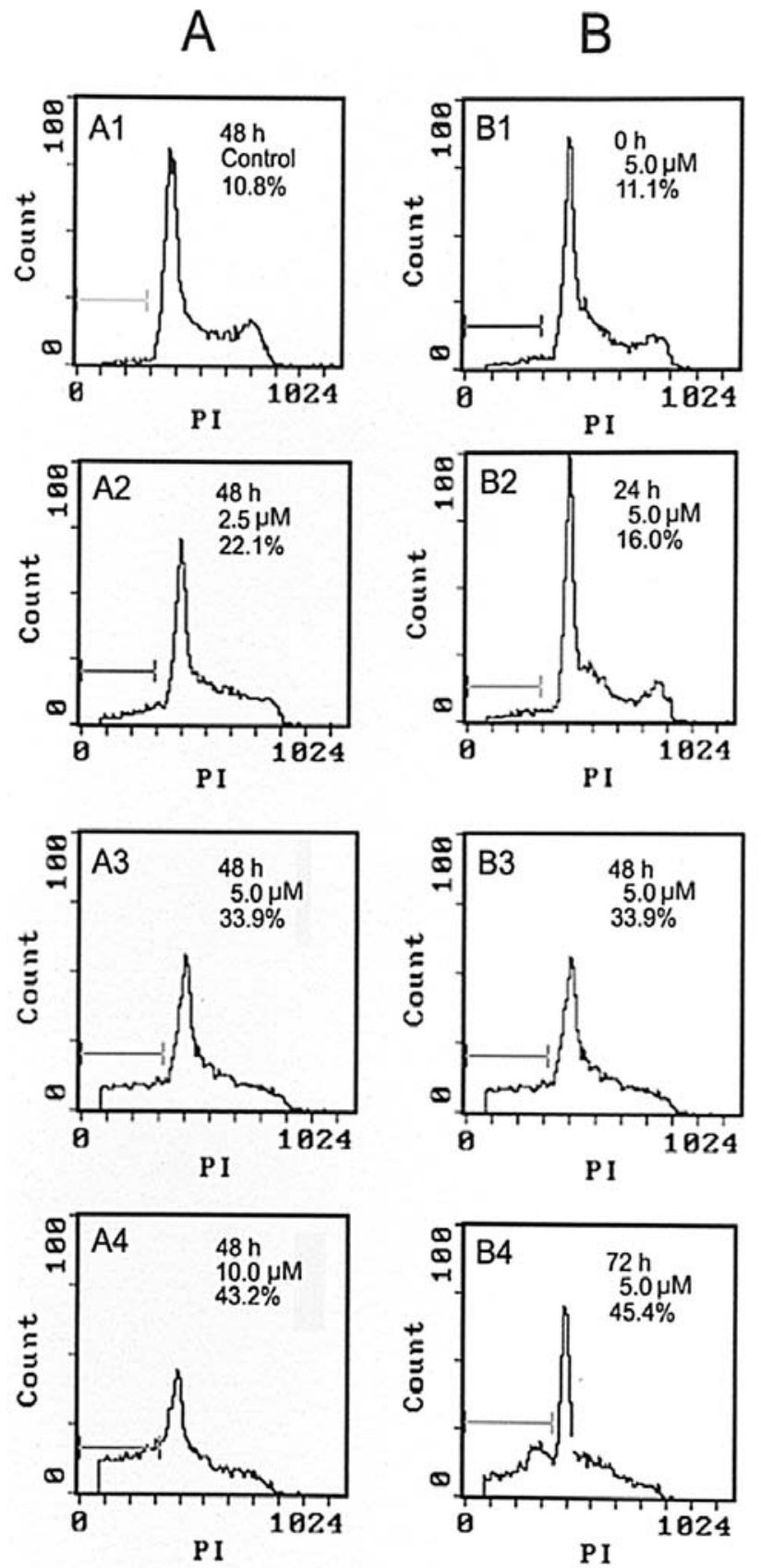

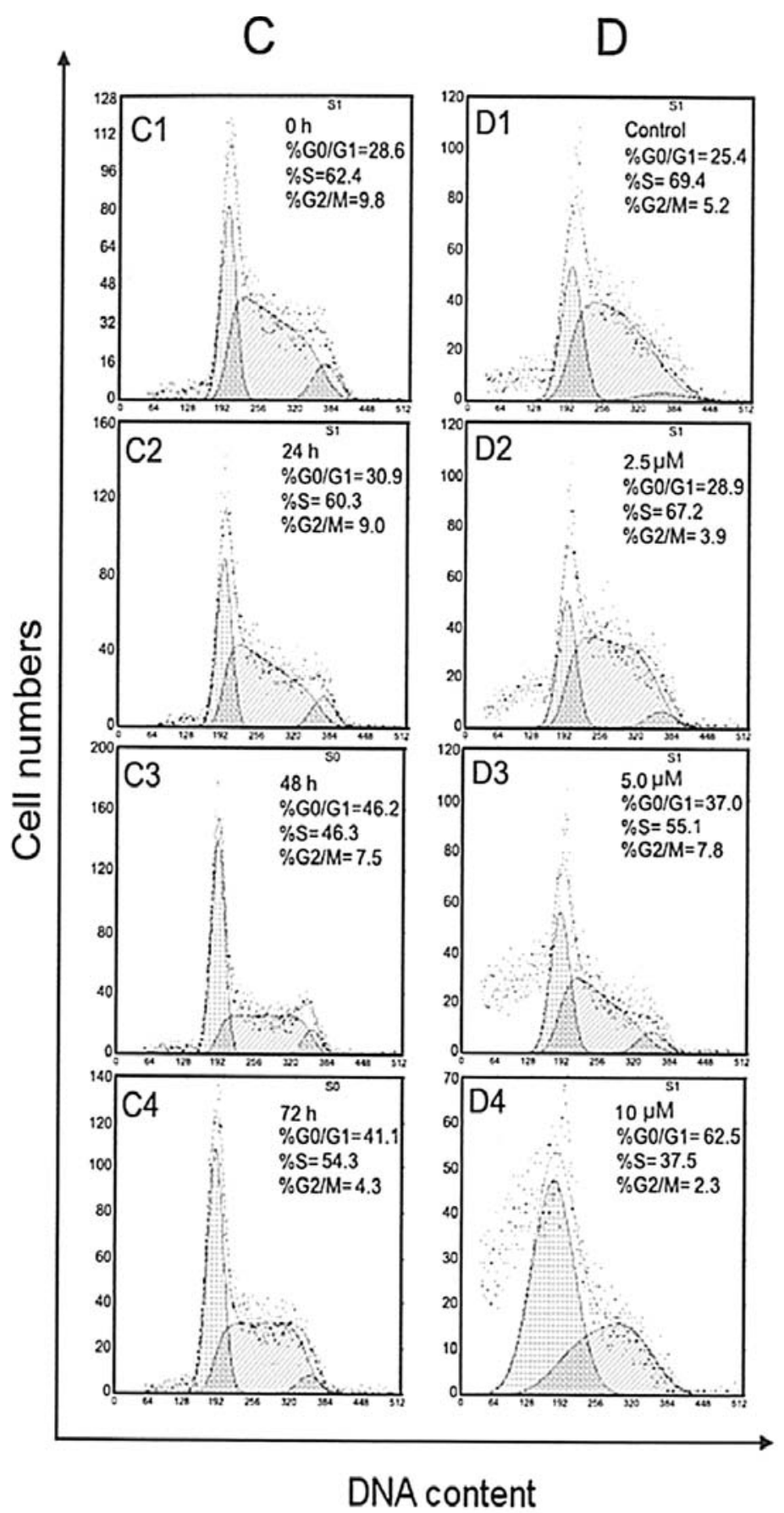

Figure 5. Lycorine augmented the apoptotic rates of the KM3 cells and the proportion of the G0/G1 phase. (A) The ratio of apoptosis increased from 10.8 to $43.2 \%$ after treatment with indicated concentrations of lycorine for $48 \mathrm{~h}$. (B) The apoptotic percentage increased from 11.1 to $45.4 \%$ after $5 \mu \mathrm{M}$ lycorine treatment for indicated times. (C) The number of cells in the G0/G1 phase increased from 28.6 to $41.4 \%$ when the cells were treated with $1.25 \mu \mathrm{M}$ lycorine at different times. (D) The number of cells in the G0/G1 phase increased from 25.4 to $62.5 \%$ after treatment with different concentrations of lycorine for 48 h.

The immunofluorescence of cytochrome $\mathrm{c}$ was visualized under a confocal laser microscope. In both groups, the nucleus was observed to be blue, from staining the DNA with Hochest33258 (Fig. 7A1 and B1) and the cytochrome c red, from staining with $\mathrm{Cy} 3$ fluorochrome (Fig. 7A2 and B2). After the cells were treated with $5 \mu \mathrm{M}$ lycorine for $24 \mathrm{~h}$, the staining patterns of cytochrome $\mathrm{c}$ became diffuse and blurred (Fig. 7B2), contrasting with the compact-plaque appearance of cytochrome $\mathrm{c}$ in the control group (Fig. 7A2), indicating the translocation of cytochrome $\mathrm{c}$ from the mitochondria into the cytosol. We also found that some red dye entered the nucleus, mixing with the blue stain to yield the purple staining of the nucleus (Fig. 7B3).

Decreases in Bcl-2, cyclin D1, and CDK4 and an increase in $B a x$. The effect of lycorine on the expression of Bcl-2, Bax, cyclin D1, and CDK4 proteins was determined by Western immunoblot analysis in order to explore the possible mechanisms underlying the lycorine-induced apoptosis of the KM3 cells (Fig. 8A). $\alpha$-tubulin was used to normalize and verify the protein loading. After being induced by lycorine, the $\mathrm{Bcl}-2$, cyclin $\mathrm{D}$, and CDK4 expression significantly 


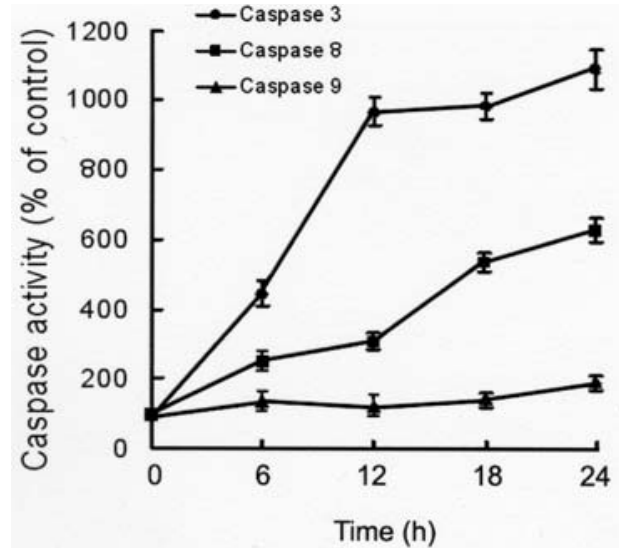

Figure 6. Determination of the activation of caspase- $8,-9$ and -3 in the KM3 cells treated with lycorine. The KM3 cells were treated with lycorine $(5 \mu \mathrm{M})$ for the indicated time before the caspase- 8 substrate, IETD-pNA, the caspase-9 substrate, LEHD-pNA, or the caspase-3 substrate, DEVD-pNA $(50 \mathrm{mM})$ were added. The mixtures were incubated for $1.5 \mathrm{~h}$ at $37^{\circ} \mathrm{C}$ followed by the measurement of the absorbance at $405 \mathrm{~nm}$. The percentage increases in the caspase activities were determined by comparing the results at the indicated time points with the level of the control. Each value represents the means \pm S.D. of 3 independent experiments.

decreased in a dose-dependent manner, whereas the Bax protein levels increased slightly (Fig. 8B and C).

\section{Discussion}

The knowledge about the importance of overcoming antiapoptosis or directly inducing apoptosis in the treatment of a variety of malignancies, including MM, raises new hope of improving treatment outcomes for patients with cancer (35-37). The value of targeting therapies that aim to induce apoptotic processes in MM cells has been explored in a number of experimental systems, and many potential new therapies for leukemia are emerging, including using thalidomide (38), proteasome inhibitors (39), and arsenic compounds (40), although the use of these agents is still limited.

Our data show that lycorine significantly inhibited the proliferation of the human MM cell line, KM3, after treatment at a half-effective concentration of $1.25 \mu \mathrm{M}$. Laser confocal microscopy and DNA fragmentation assay suggested the occurrence of apoptosis. The efficacy of lycorine in inducing MM cell apoptosis was proven in the present experiments.

Apoptosis plays critical roles in tissue homeostasis (41). Apoptosis is caused by the activation of the intracellular proteases known as caspases. When cleaved, numerous cellular targets of caspases can aggregate to produce the characteristic morphological changes called apoptosis. Several caspases, mediated by various anti-tumor drugs, have been shown to be key executors of apoptosis (42). Several pathways exist for triggering caspase activation, and between these, intrinsic and extrinsic pathways have been elucidated in detail and have been the center of attention in past years (43).

The intrinsic apoptotic pathway focuses on the mitochondria as the initiators of cell death. Multiple signals converge on mitochondria, causing these organelles to release cytochrome $\mathrm{c}$ and other apoptogenic proteins into the cytosol, where cytochrome $\mathrm{c}$ binds to the apoptotic peptidase activating factor 1 (Apaf1), then procaspase-9, forming apoptosome to
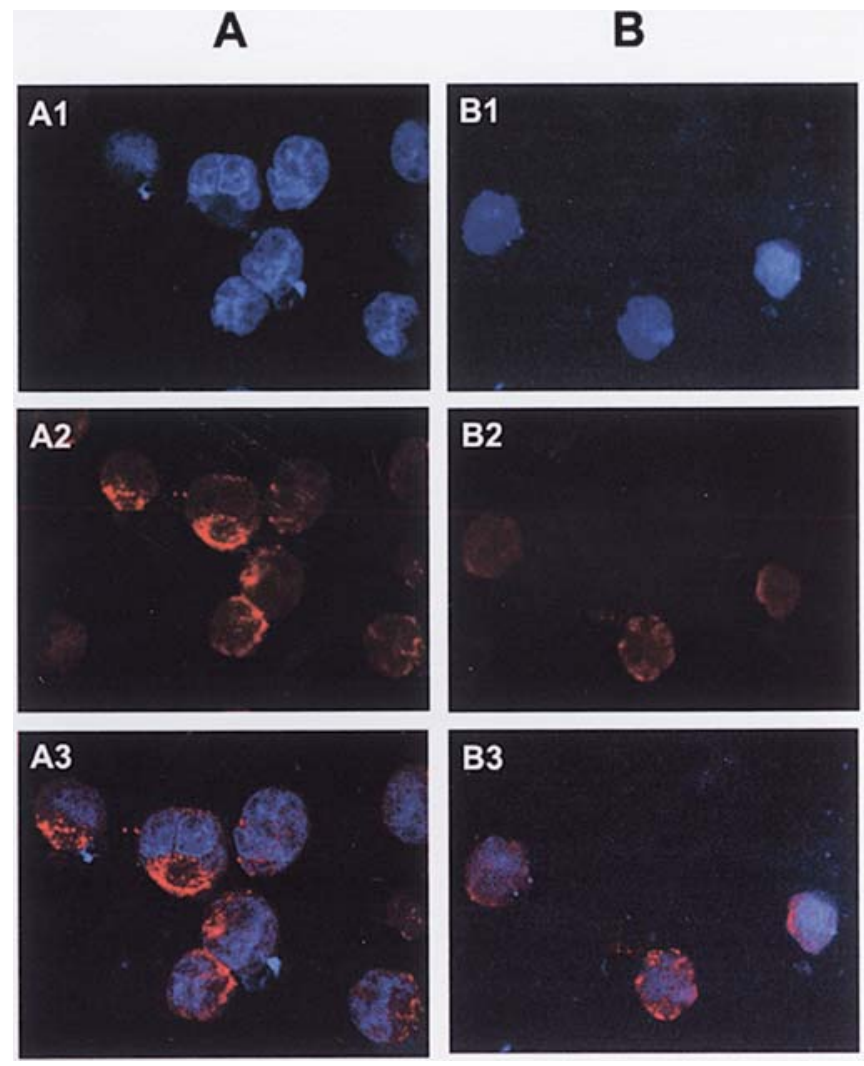

Figure 7. The effects of lycorine on the cytochrome c release from the mitochondria. The KM3 cells were fixed and labeled for cytochrome c (red) and DNA (blue). (A) The untreated cells as the control, (B) The KM3 cells treated with $5 \mu \mathrm{M}$ lycorine for $24 \mathrm{~h}$. The cell nuclei are seen by DNA staining with 4'6-diamidino-2-phenyl indole (DAPI) (A1 and B1). Cytochrome c became diffusive in most cells (B2), consistent with its translocation into the cytosol and nucleus (B3), whereas it displayed a dotted pattern in the untreated cells, consistent with its location within the mitochondria (A2 and A3). The images were obtained with a confocal laser microscope (x1000).

activate caspase-9, and finally activating downstream effector proteases, such as procaspase-3 (44). In contrast, the extrinsic apoptotic pathway relies on the death receptors of the tumor necrosis factor (TNF) family to bind with death ligands and subsequently activate caspase- 8 and -3 for triggering apoptosis (45).

It can be seen that caspases are always at the center of the apoptotic procedure. The Bcl-2 protein family, which consists of anti-apoptotic (e.g. Bcl-2) and pro-apoptotic members (e.g. Bax) (46), is an important regulator of apoptosis. Our results indicate that lycorine can induce the release of cytochrome $\mathrm{c}$ from the mitochondria into either the cytoplasm or the cytoblast. We found the activation of caspase- 8 and -3 to be involved in lycorine-induced apoptosis. Therefore, we concluded that both the intrinsic and extrinsic pathways were involved in the lycorine-induced apoptosis. Furthermore, we have shown that lycorine can increase the Bax protein levels and markedly decrease the Bcl-2 protein levels. To summarize, we have demonstrated that the lycorine-induced apoptosis of the KM3 cells is associated with inducing the release of cytochrome $\mathrm{c}$ from the mitochondria, activating caspase- 8 and -3 , as well as increasing the Bax levels and decreasing the Bcl-2 levels.

The genetic and biochemical investigations of the molecular mechanisms governing the $\mathrm{G} 1$ to $\mathrm{S}$ phase progression in 
A

1

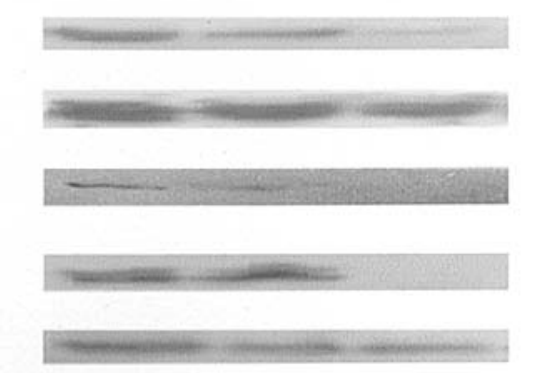

$\mathrm{Bcl}-2$

Bax

cyclin D1

CDK 4

a-tubulin
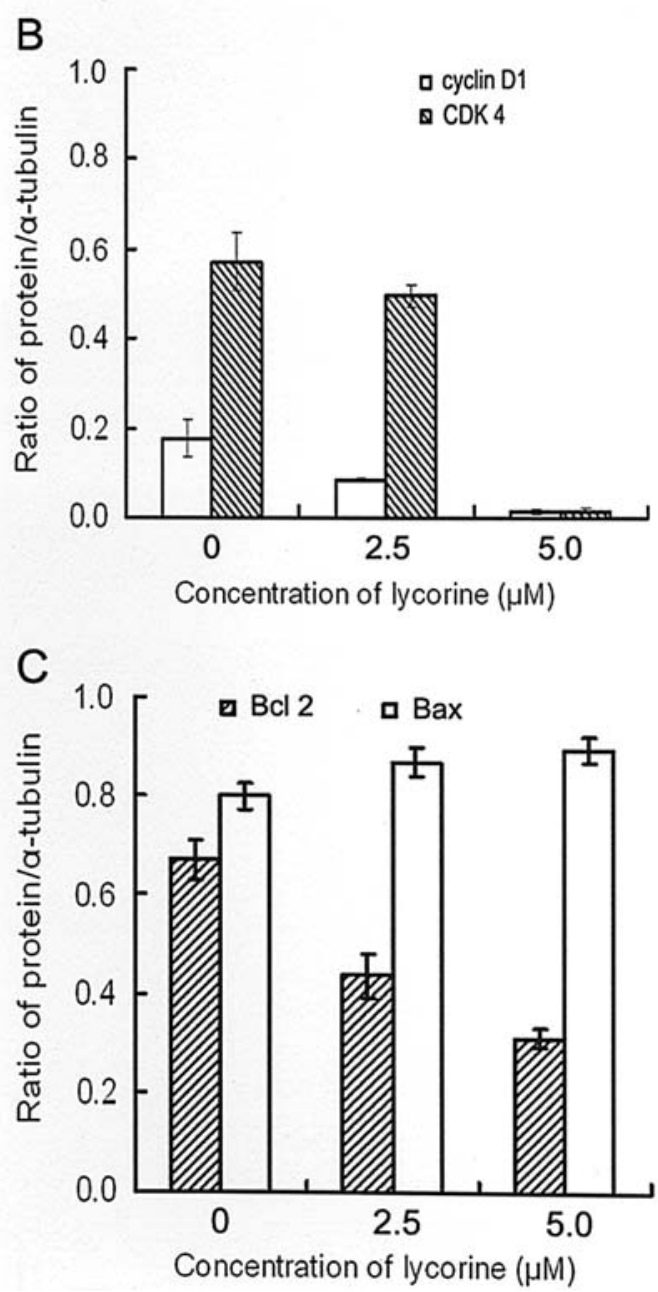

Figure 8. The effects of lycorine on the expression level of Bcl-2, Bax, cyclin D1 and CDK4 in the KM3 cells. The exponentially growing KM3 cells were treated with indicated concentrations of lycorine for $24 \mathrm{~h}$, cell lysates were prepared and the protein level was determined by Western immunoblot analysis. (A) The expression of Bcl-2, Bax, cyclin D1 and CDK4 after lycorine treatment. $\alpha$-tubulin was used for the normalization and verification of the protein loading. Lane 1, control; lanes 2 and 3, KM3 cells treated by 2.5 , or $5 \mu \mathrm{M}$ lycorine, respectively. (B) The relative level of the cyclin D1 and CDK4 expression after normalization to $\alpha$-tubulin. The expression level of both proteins was decreased significantly when the concentrations of lycorine were increased in the culture. (C) The relative level of the Bcl-2 and Bax expression after normalization to $\alpha$-tubulin. The expression of Bcl-2 was decreased significantly while the Bax protein level was increased slightly when the concentrations of lycorine were increased in the culture.

mammalian cells have demonstrated a critical role for D-type cyclins and their partners, CDKs 4 and 6 (20,21,47-49). The level of the cyclin D1 protein was found to be a prognostic marker of disease outcomes for different malignancies. Alterations in different proteins that control the cell cycle progression can be of substantial importance in determining the sensitivities of cells and tumors to some reagents (21). The overexpression of cyclin D1 and CDK4, as well as the dysregulation of growth factors in MM cells, were associated with abnormal proliferation and drug resistance $(10,23,49,50)$. In this study, an increase in the G0/G1 phase cells was observed after the lycorine treatment. Moreover, this study revealed that lycorine suppressed the cyclin D1 and CDK4 gene expression. Therefore, the anti-overexpression of the cyclin D1 and CDK4 gene, could be the mechanism of the lycorine-induced cell cycle arrest of KM3 at the G0/G1 phase.

In the present experiment, we found an increased expression of Bax but a decreased expression of Bcl-2, cyclin D1, and CDK4 proteins in the inhibited cells. Although the order of all these events has not been determined and the relationship of apoptosis and cell arrest is unclear, it can be concluded that a relationship exists between the lycorineinduced cell cycle arrest of KM3 at the G0/G1 phase and both the intrinsic mitochondria and the extrinsic deathreceptor pathway of apoptosis through the regulation of the expression of some pro-apoptotic molecules in the KM3 cells. Our results suggest that lycorine could be a potential novel chemotherapeutical compound for the treatment of MM.

\section{Acknowledgements}

This study was supported by grants from the National Natural Science Foundation of China (Nos. 39880021, 30270750, 30300406, 30400529, and 30500269).

\section{References}

1. Attal M, Harousseau JL, Stoppa AM, et al: A prospective randomized trial of autologous transplantation and chemotherapy in multiple myeloma. N Engl J Med 335: 91-97, 1996.

2. Barlogie B, Shaughnessy J, Tricot G, et al: Treatment of multiple myeloma. Blood 103: 20-32, 2004.

3. Rajkumar SV and Kyle RA: Multiple myeloma: diagnosis and treatment. Mayo Clin Proc 80: 1371-1382, 2005.

4. Kuehl W and Bergsagel P: Multiple myeloma: evolving genetic events and host interactions. Nat Rev Cancer 2: 175-187, 2002.

5. Hallek M, Bergsagel P and Anderson K: Multiple myeloma: increasing evidence for a multistep transformation process. Blood 91: 3-21, 1998.

6. Kyle RA, Therneau TM, Rajkumar SV, Offord JR, Larson DR, Plevak MF and Melton LJ III: A long-term study of prognosis in monoclonal gammopathy of undetermined significance. N Engl J Med 346: 564-569, 2002.

7. Avet-Loiseau H, Facon T, Daviet A, et al: 14q32 translocations and monosomy 13 observed in monoclonal gammopathy of undetermined significance delineate a multistep process for the oncogenesis of multiple myeloma. Intergroupe Francophone du Myelome. Cancer Res 59: 4546-4550, 1999.

8. Zhan F, Hardin J, Kordsmeier B, et al: Global gene expression profiling of multiple myeloma, monoclonal gammopathy of undetermined significance and normal bone marrow plasma cells. Blood 99: 1745-1757, 2002.

9. Wu K, Orme L, Shaughnessy J, Bumm K, Barlogie B and Moore M: Telomerase and telomere length in multiple myeloma: correlations with disease heterogeneity, cytogenetic status and overall survival. Blood 101: 4982-4989, 2003.

10. Van De Donk NW, Lokhorst HM and Bloem AC: Growth factors and antiapoptotic signaling pathways in multiple myeloma. Leukemia 19: 2177-2185, 2005.

11. Yang E and Korsmeyer SJ: Molecular thanatopsis: a discourse on the bcl-2 family and cell death. Blood 88: 386-401, 1996. 
12. Korsmeyer SJ: Bcl-2 initiates a new category of oncogenes: regulators of cell death. Blood 80: 879-886, 1992.

13. Reed JC: Bcl-2 family proteins. Oncogene 17: 3225-3236, 1998.

14. Tian E and Gazitt Y: The role of P53, Bcl-2 and bax in dexamethasone induced apoptosis in myeloma cell lines. Int $\mathbf{J}$ Oncol 8: 719-726, 1996.

15. Hu W-X and Gazitt Y: Bcl-2 plays a major role in resistance to dexamethasone induced apoptosis in multiple myeloma cell lines. Int J Oncol 9: 375-381, 1996

16. Gazitt Y, Rothenberg ML, Hilsenbeck SG, Fey V, Thomas C and Montegomrey W: Bcl-2 overexpression is associated with resistance to paclitaxel, but not gemcitabine, in multiple myeloma cell lines. Int J Oncol 13: 839-848, 1998.

17. Liu Q and Gazitt Y: Adenovirus-mediated delivery of p53 results in a substantial apoptosis to myeloma cells and is not cytotoxic to flow-sorted $\mathrm{CD} 34^{+}$hematopoietic progenitor cells and normal lymphocytes. Exp Hematol 28: 1354-1362, 2000.

18. Liu Q and Gazitt Y: Potentiation of dexamethasone-, paclitaxel-, and Ad-p53-induced apoptosis by Bcl-2 antisense oligodeoxynucleotides in drug-resistant multiple myeloma cells. Blood 101: 4105-4114, 2003.

19. Strauss M, Lukas J and Bartek J: Unrestricted cell cycling and cancer. Nat Med 1: 1245-1246, 1995.

20. Weinberg RA: The retinoblastoma protein and cell cycle control. Cell 81: 323-330, 1995.

21. Hall M and Peters G: Genetic alterations of cyclins, cyclindependent kinases, and Cdk inhibitors in human cancer. Adv Cancer Res 68: 67-108, 1996.

22. Hunter T and Pines J: Cyclins and cancer II: cyclin D and CDK inhibitors come of age. Cell 79: 573-582, 1994.

23. Kramer A, Schultheis B, Bergmann J, et al: Alterations of the cyclin $\mathrm{D} 1 / \mathrm{pRb} / \mathrm{p} 16^{\mathrm{INK} 4 \mathrm{~A}}$ pathway in multiple myeloma. Leukemia 16: 1844-1851, 2002.

24. Jimenez A, Santos A, Alonso G and Vazquez D: Inhibitors of protein synthesis in eukaryotic cells. Comparative effects of some amaryllidaceae alkaloids. Biochim Biophys Acta 425: 342-348, 1976.

25. Vrijsen R, Vanden Berghe DA, Vlietinck AJ and Boeye A: Lycorine: a eukaryotic termination inhibitor? J Biol Chem 261: 505-507, 1986.

26. Lopez, S, Bastida J, Viladomat F and Codina C: Acetylcholinesterase inhibitory activity of some Amaryllidaceae alkaloids and Narcissus extracts. Life Sci 71: 2521-2529, 2002.

27. Elgorashi EE, Stafford GI and Van Staden J: Acetylcholinesterase enzyme inhibitory effects of amaryllidaceae alkaloids. Planta Med 70: 260-262, 2004.

28. Bilge T, Ilkay O and Jutamad S: Antimalarial activity screening of some alkaloids and the plant extracts from Amaryllidaceae. Phytother Res 17: 1220-1223, 2003.

29. Yui S, Mikami M, Kitahara M and Yamazaki M: The inhibitory effect of lycorine on tumor cell apoptosis induced by polymorphonuclear leukocyte-derived calprotectin. Immunopharmacology 40: 151-162, 1998.

30. Liu J, Hu WX, He LF, Mao Y and Li Y: Effects of lycorine on HL-60 cells via arresting cell cycle and inducing apoptosis. FEBS Lett 578: 245-250, 2004.

31. Nakamura M, Kudo T, Narimatsu H, et al: Single glycosyltransferase, core $2 \beta 1 \rightarrow 6-\mathrm{N}$-acetylglucosaminyltransferase, regulates cell surface sialyl-Le ${ }^{\mathrm{x}}$ expression level in human pre-B lymphocytic leukemia cell line KM3 treated with phorbolester. J Biol Chem 273: 26779-26789, 1998.
32. Gazitt Y and Erdos GW: Fluctuation and ultrastructural localization of oncogenes and cell cycle regulatory proteins during growth and apoptosis of AGF cells. Cancer Res 54: 950-956, 1994

33. Sellins KS and Cohen JJ: Gene induction by gamma-irradiation leads to DNA fragmentation in lymphocytes. J Immunol 139: 3199-3206, 1987.

34. Mehmet H: Apoptosis: caspase and a new place to hide. Nature 403: 29-30, 2002 .

35. Thompson CB: Apoptosis in the pathogenesis and treatment of disease. Science 267: 1456-1462, 1995

36. Reed JC: Apoptosis-regulating proteins as targets for drug discovery. Trends Mol Med 7: 314-319, 2001

37. Sawyers C: Targeted cancer therapy. Nature 432: 294-297, 2004

38. Mitsiades N, Mitsiades CS, Poulaki V, et al: Apoptotic signaling induced by immunomodulatory thalidomide analogs in human multiple myeloma cells: therapeutic implications. Blood 99: 4525-4530, 2002.

39. Pei XY, Dai Y and Grant S: The proteasome inhibitor bortezomib promotes mitochondrial injury and apoptosis induced by the small molecule Bcl-2 inhibitor HA14-1 in multiple myeloma cells. Leukemia 17: 2036-2045, 2003.

40. Rousselot P, Labaume S, Marolleau JP, Larghero J, Noguera MH, Brouet JC and Fermand JP: Arsenic trioxide and melarsoprol induce apoptosis in plasma cell lines and in plasma cells from myeloma patients. Cancer Res 59: 1041-1048, 1999.

41. Hengartner MO: The biochemistry of apoptosis. Nature 407: 770-776, 2000

42. Boatright KM and Salvesen GS: Mechanisms of caspase activation. Curr Opin Cell Biol 15: 725-731, 2003.

43. Salvesen GS: Caspases: opening the boxes and interpreting the arrows. Cell Death Differ 9: 3-5, 2002

44. Salvesen GS and Renatus M: Apoptosome: the seven-spoked death machine. Dev Cell 2: 256-257, 2002.

45. Wallach D, Varfolomeev EE, Malinin NL, Goltsev YV, Kovalenko AV and Boldin MP: Tumor necrosis factor receptor and Fas signaling mechanisms. Annu Rev Immunol 17: 331-367, 1999.

46. Cory S, Huang DC and Adams JM: The Bcl-2 family: roles in cell survival and oncogenesis. Oncogene 22: 8590-8607, 2003.

47. Hartwell LH and Weinert TA: Checkpoints: controls that ensure the order of cell cycle events. Science 246: 629-634, 1989.

48. Agami R and Bernards R: Distinct initiation and maintenance mechanisms cooperate to induce G1 cell cycle arrest in response to DNA damage. Cell 102: 55-66, 2000.

49. Ely S, Di Liberto M, Niesvizky R, et al: Mutually exclusive cyclin-dependent kinase 4/cyclin D1 and cyclin-dependent kinase 6/cyclin D2 pairing inactivates retinoblastoma protein and promotes cell cycle dysregulation in multiple myeloma. Cancer Res 65: 11345-11353, 2005.

50. Zhang T, Nanney LB, Luongo C, Lamps L, Heppner KJ, DuBois RN and Beauchamp RD: Concurrent overexpression of cyclin D1 and cyclin-dependent kinase $4(\mathrm{Cdk} 4)$ in intestinal adenomas from multiple intestinal neoplasia (Min) mice and human familial adenomatous polyposis patients. Cancer Res 57: 169-175, 1997. 